Pesq. Vet. Bras. 28(10):488-494, outubro 2008

\title{
Intoxicação experimental por Ipomoea asarifolia (Convolvulaceae) em caprinos e ovinos ${ }^{1}$
}

\author{
José A.S. Araújo ${ }^{2}$, Franklin Riet-Correa ${ }^{3^{*}}$, Rosane M.T. Medeiros ${ }^{3}$, Mauro P. \\ Soares $^{4}$, Diego M. Oliveira ${ }^{2}$ e Fabricio K.L. Carvalho ${ }^{5}$
}

ABSTRACT.- Araujo J.A.S., Riet-Correa F., Medeiros R.M.T., Soares M.P., Oliveira D.M.
\& Carvalho F.K.L. 2008. [Experimental poisoning by Ipomoea asarifolia (Convolvula-
ceae) in goats and sheep.] Intoxicação experimental por Ipomoea asarifolia (Convolvula-
ceae) em caprinos e ovinos. Pesquisa Veterinária Brasileira 28(10):488-494. Hospital
Veterinário, CSTR, Campus de Patos, Universidade Federal de Campina Grande, Patos,
PB 58700-000, Brazil. E-mail: franklin.riet@ @pq.cnpq.br
Ipomoea asarifolia causes a tremogenic syndrome in sheep, goats, cattle and buffaloes. The objectives of the experiments were (1) to determine the toxicity to goats of fresh $I$. asarifolia collected during the raining and the dry season, and the toxicity of the dried plant, and (2) to determine the toxicity of the plant to sheep, and if the active principle is eliminated through the milk. In the first experiment the plant collected in the dry season and in the raining season was fed to 16 goats. The plant collected during the dry season caused clinical signs at the daily doses of $5 \mathrm{~g}$ and $10 \mathrm{~g} / \mathrm{kg}$ body weight. The plant collected during the raining season was toxic at daily doses of $20 \mathrm{~g}$ and $30 \mathrm{~g} / \mathrm{kg}$, indicating that the plant is more toxic during the dry season. The plant collected in the dry season and dried was fed to 9 goats at doses of $1.7 \mathrm{~g}, 2.0 \mathrm{~g}, 3.4 \mathrm{~g}$, and $5.1 \mathrm{~g}$ per $\mathrm{kg}$. Daily doses of $3.0 \mathrm{~g}, 4.0 \mathrm{~g}$ and $5.1 \mathrm{~g} /$ $\mathrm{kg}$ caused clinical signs, showing that the plant maintains its toxicity after being dried. In the second experiment the fresh plant collected in the dry and in the raining season was fed to 10 sheep. The plant collected in the dry season was toxic at the dose of $5 \mathrm{~g} / \mathrm{kg}$, and the plant collected in the raining season was toxic at the doses of $10 \mathrm{~g}$ and $20 \mathrm{~g} / \mathrm{kg}$. The experimental results suggest that sheep are more susceptible to the poisoning than goats. As some farmers mentioned that suckling non-grazing lambs are poisoned by milk ingestion, I. asarifolia was fed at daily doses of $2.5 \mathrm{~g}, 5.0 \mathrm{~g}$ and $10 \mathrm{~g} / \mathrm{kg}$ for variable periods to 5 sheep from the day of parturition (2 sheep), after the last day of pregnancy (1 sheep) and 60 days before parturition (2 sheep). The sheep but not the lambs showed clinical signs of intoxication suggesting that the active principle is not eliminated through the milk at doses toxic for the lambs. In one euthanized sheep no gross or histologic lesions were detected. The main ultra-structural findings were found in Purkinje cell dendrites and included swelling, decrease or absence of dendritic spines, decrease or absence of neurotubules and neurofilaments and vacuolation of the dendroplasm. Swelling of the smooth endoplasmic reticulum and granular eletrondense inclusions in dendroplasm was observed. Swelling of astrocyte foot processes was conspicuous. It is suggested that these alterations are a result of continuous

\footnotetext{
${ }^{1}$ Recebido em 28 de março de 2008.

Aceito para publicação em 29 de maio de 2008.

2 Pós-Graduando de Mestrado em Medicina Veterinária em Ruminantes e Eqüídeos, Hospital Veterinário, CSTR, Universidade Federal de Campina Grande (UFCG), Patos, PB 58700-000, Brasil. E-mail: araujojas@yahoo.com.br.

${ }^{3}$ Centro de Saúde e Tecnologia Rural (CSTR), UFCG, Campus
}

de Patos, 58700-000 Patos, PB. *Autor para correspondência: franklin.riet@pq.cnpq.br

${ }^{4}$ Laboratório Regional de Diagnóstico, Faculdade de Medicina Veterinária, Universidade Federal de Pelotas (UFPEL), Pelotas, RS 96010900, Brasil.

${ }^{5}$ Bolsista de Iniciação Científica, UFCG, Campus de Patos, 5870000 Patos, PB. 
tremors induced by the plant with liberation of glutamate causing excitotoxicity, which probably constitutes a neuronal mechanism of defense.

INDEX TERMS: Toxic plants, Ipomoea asarifolia, goats, sheep, plant poisoning, Purkinje cells, swollen dendrites, exitotoxicity, tremogenic toxins.

RESUMO.- Ipomoea asarifolia causa uma síndrome tremorgênica em ovinos, caprinos, bovinos e búfalos. Este experimento teve como objetivos determinar a toxicidade para caprinos de I. asarifolia verde, colhidas nas épocas de chuva e de estiagem, e da planta seca triturada, determinar a toxicidade da planta para ovinos, e determinar se o princípio ativo da planta é eliminado pelo leite em doses tóxicas para os cordeiros. No primeiro experimento a planta fresca colhida na época de estiagem e na época de chuvas foi administrada a 16 caprinos. A planta colhida na estiagem foi tóxica na dose diária de 5 e $10 \mathrm{~g}$ por $\mathrm{kg}$ de peso animal $(\mathrm{g} / \mathrm{kg})$. A planta colhida na época de chuva foi tóxica na dose diária de 20 e $30 \mathrm{~g} / \mathrm{kg}$, demonstrando que a planta é mais tóxica durante o período seco. A planta seca, colhida na época de estiagem foi administrada a 9 caprinos em doses diárias de 1.7, 2, 3.4 e $5.1 \mathrm{~g} / \mathrm{kg}$. Doses de 3,4 e $5.1 \mathrm{~g} / \mathrm{kg}$ causaram sinais clínicos, demonstrando que a planta mantém a toxicidade após a secagem. A planta fresca colhida na época de estiagem e na época de chuvas foi administrada a 10 ovinos. A planta colhida na estiagem foi tóxica na dose diária de $5 \mathrm{~g} / \mathrm{kg}$ e na época de chuva foi tóxica nas doses de 10 e $20 \mathrm{~g} / \mathrm{kg}$. Estes resultados sugerem a maior susceptibilidade dos ovinos à intoxicação do que os caprinos. Como alguns produtores mencionam que cordeiros lactentes que não estão pastando se intoxicam através do leite, I. asarifolia foi administrada diariamente nas doses de 2.5, 5 e $10 \mathrm{~g} / \mathrm{kg}$ a 5 ovelhas, a partir do dia do parto (2 ovelhas), do último dia de prenhez (1 ovelha) e 60 dias antes da parição (2 ovelhas). As ovelhas, mas não os cordeiros, apresentaram sinais clínicos, sugerindo que o princípio ativo da planta não é eliminado no leite ou colostro em doses tóxicas para os cordeiros. Em um ovino eutanasiado não foram observadas lesões macroscópicas nem histológicas. Os achados ultra-estruturais mais significativos foram encontrados nos dendritos das células de Purkinje e incluíam tumefação, decréscimo ou ausência das espículas dendríticas, diminuição ou ausência de neurotúbulos e neurofilamentos, vacuolizações do dendroplasma, tumefação do retículo endoplasmático liso e inclusões eletro-densas no dendroplasma. Tumefação dos processos astrocitários era bastante evidente. Sugere-se que essas alterações, que provavelmente constituam um mecanismo de defesa neuronal, sejam resultado dos tremores induzidos pela substância ou substâncias tóxicas contidas na planta, com liberação de glutamato no espaço extracelular que causa excitotoxicidade.

TERMOS DE INDEXACÃO: Caprinos, células de Purkinje, excitotoxicidade, Ipomoea asarifolia, ovinos, plantas tóxicas, toxinas tremorgênicas, tumerfação de dendritos.

\section{INTRODUÇÃO}

Ipomoea asarifolia R. et Schult. (Fig.1) (nome comum: salsa), da família Convolvulaceae, é uma planta nativa na

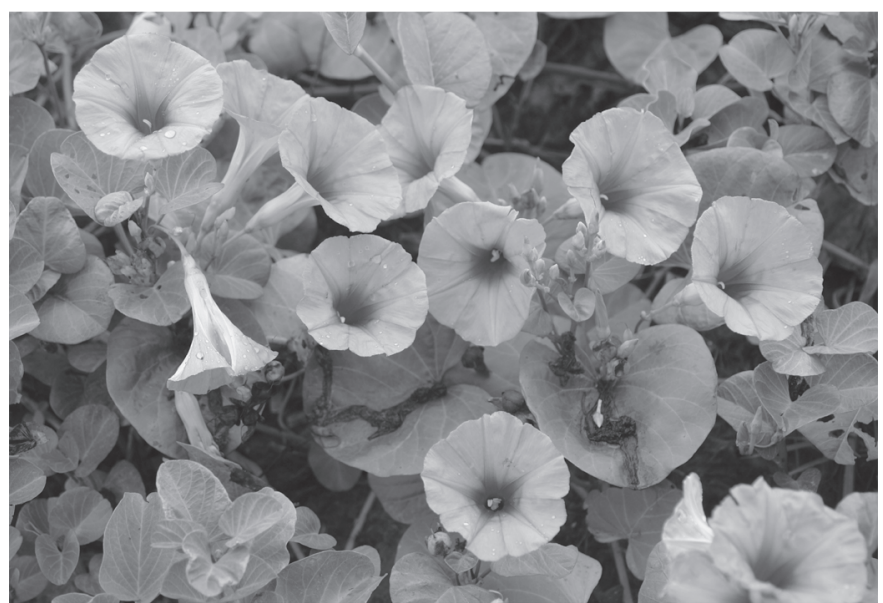

Fig.1. Ipomoea asarifolia (salsa), município de Patos, Paraíba.

América tropical, que ocorre em regiões da América do Sul e Central. No Brasil é muito comum na Amazônia e em todo o litoral da região Norte até os estados do Rio de Janeiro e São Paulo e região Nordeste (Kissmann \& Groth 1992). É encontrada às margens de rios e lagoas, praias marítimas, em terrenos abandonados e nas margens das estradas (Tokarnia et al. 2000). No semi-árido é encontrada as margens de açudes e rios, em terrenos abandonados, nas margens de estradas, em áreas de baixios e próximos a reservatórios de água.

Ipomoea asarifolia causa intoxicação em ovinos (Döbereiner et al. 1960, Tokarnia et al. 2000, Riet-Correa et al. 2003, Guedes et al. 2007), caprinos (Döbereiner et al. 1960, Tokarnia et al. 2000, Riet-Correa et al. 2003, Medeiros et al. 2003, Guedes et al. 2007) e bovinos (Döbereiner et al. 1960, Tokarnia et al. 2000, Riet-Correa et al. 2003, Barbosa et al. 2005). A intoxicação foi reproduzida experimentalmente em búfalos, mas a doença espontânea não tem sido observada nesta espécie (Barbosa et al. 2005). Os bovinos são, aparentemente, mais susceptíveis à intoxicação por I. asarifolia e desenvolvem a enfermidade após um único dia de consumo (Döbereiner et al. 1960). Os búfalos apresentam sensibilidade semelhante à dos bovinos, com a diferença que os sinais de incoordenação são menos acentuados do que nos bovinos, com a tendência dos búfalos permanecerem em decúbito esternal (Barbosa et al. 2005). A intoxicação ocorre, principalmente, durante as estações secas, quando os animais, devido a pouca disponibilidade de forragem, ingerem grandes quantidades desta planta, durante algumas semanas, como fonte principal de alimento. Desconhece-se se há variações de toxicidade da planta em diferentes épocas do ano. A intoxicação é mais freqüente em ovinos do que em outras espécies, afetando principalmente ovinos jovens e lactentes (Riet-Correa 
et al. 2003, Barbosa et al. 2005, Guedes et al. 2007). Desconhece-se se esta maior freqüência deve-se a uma maior susceptibilidade dos ovinos ou a que estes animais ingerem a planta com maior facilidade. Na intoxicação em ovinos chama a atenção que em alguns surtos são afetados animais muito jovens o que sugere que a toxina tremorgênica de $I$. asarifolia seja eliminada pelo leite. Além disso, um produtor do Ceará relatou que cordeiros filhos de ovelhas ingerindo salsa são afetados mesmo que permaneçam encerrados em quanto às mães estão pastejando em áreas com salsa. Esses fatos sugerem ha necessidade de se estudar a provável eliminação pelo leite da toxina da planta.

Estes experimentos tiveram como objetivos: determinar se há diferenças de toxicidade de $I$. asarifolia para caprinos na época de chuva e na estiagem; determinar a toxicidade da planta seca; determinar a toxicidade da planta para ovinos; determinar se o princípio ativo é excretado pelo leite; e realizar estudos histológicos e de microscopia eletrônica de transmissão.

\section{MATERIAL E MÉTODOS}

Os experimentos foram realizados no Hospital Veterinário da Universidade Federal de Campina Grande (UFCG), Campus de Patos, Paraíba. Ipomoea asarifolia usada nos experimentos foi colhida nos arredores do Hospital Veterinário. A planta fresca foi colhida imediatamente antes de sua administração. A planta, colhida para experimento sob forma dessecada, foi colhida na época de estiagem, colocada para secar na sombra durante 20 dias, triturada e administrada aos caprinos. Os caprinos e ovinos antes de iniciar o experimento, passaram por um período de adaptação e foram vermifugados. Todos os animais receberam feno de Cynodon dactylon (capim Tifton) e água à vontade mais ração comercial em quantidade equivalente a $1 \%$ do peso vivo.

\section{Toxicidade de Ipomoea asarifolia para caprinos nas épocas de estiagem e de chuvas}

Foram utilizados 18 caprinos, Moxotó, com idades de 4 a 12 meses, sendo 16 experimentais e 2 controles. As doses e o tipo de planta administrada, colhida na época na estiagem e na chuvosa, apresentam-se no Quadro 1.

\section{Toxicidade de Ipomoea asarifolia seca para caprinos}

Foram utilizados 11 caprinos, Moxotó, com idade de 4 a 12 meses, sendo 9 experimentais e 2 controles. As doses e o tipo de planta administrada, colhida na época estiagem, apresentam-se no Quadro 2. A correlação do peso de $I$. asarifolia verde recém-colhida e da planta dessecada foi determinado em duas amostras, uma da época de chuva e outra da época de seca. Para isso, a planta foi enviada para o Laboratório de Nutrição do Centro de Saúde e Tecnologia Rural da UFCG.

\section{Toxicidade de Ipomoea asarifolia para ovinos}

Foram utilizados 12 ovinos deslanados, sem raça definida, com idade de 6 meses a 2 anos, sendo 10 experimentais e 2 controles. As doses e o tipo de planta administrada, colhida na época de estiagem e na chuvosa, apresentam-se no Quadro 3. O ovino 10 recebeu a planta até o $13^{\circ}$ dia e no $14^{\circ}$ foi eutanasiado e realizado estudo histológico do sistema nervoso central e de órgãos das cavidades abdominal e torácica e tireóides. Para microscopia eletrônica, foram coletados fragmentos do córtex do vermis cerebelar e de fragmentos da mesma localização de um ovino controle, poucos minutos após a interrupção da circulação cerebral. Pelo menos 6 fragmentos de cada caso foram fixados em solução de glutaraldeído $2 \%$, paraformaldeído $2 \%$, tamponada com cacodilato de sódio. As amostras foram pós-

Quadro 1. Toxicidade de Ipomoea asarifolia para caprinos. Doses da planta fresca, colhida nas épocas de estiagem e de chuva, ingeridas por cada caprino, peso do animal no início e no final da administração, observação dos sinais clínicos e recuperação dos animais

\begin{tabular}{|c|c|c|c|c|c|c|c|c|c|}
\hline $\begin{array}{c}\text { Caprino } \\
\text { no. }\end{array}$ & $\begin{array}{l}\text { Época de } \\
\text { coleta da } \\
\text { planta }\end{array}$ & $\begin{array}{l}\text { Peso inicial } \\
(\mathrm{kg})\end{array}$ & $\begin{array}{l}\text { Peso final } \\
(\mathrm{kg})\end{array}$ & $\begin{array}{l}\text { Dose } \\
\text { diária } \\
(\mathrm{g} / \mathrm{kg})\end{array}$ & $\begin{array}{l}\text { Dose } \\
\text { total } \\
(\mathrm{g} / \mathrm{kg})\end{array}$ & $\begin{array}{l}\text { Dias de } \\
\text { ingestão }\end{array}$ & $\begin{array}{l}\text { Início dos } \\
\text { sinais clí- } \\
\text { nicos (dia) }\end{array}$ & $\begin{array}{l}\text { Duração dos } \\
\text { sinais clíni- } \\
\text { cos (dias) }\end{array}$ & $\begin{array}{c}\text { Recuperação } \\
\text { (dias após } \\
\text { o final da } \\
\text { ingestão) }\end{array}$ \\
\hline 1 & Estiagem & 15 & 21,8 & 2,5 & 312,5 & 125 & $\mathrm{SS}^{\mathrm{a}}$ & - & - \\
\hline 2 & Estiagem & 15,5 & 21 & 2,5 & 150 & 60 & SS & - & - \\
\hline 3 & Estiagem & 13,5 & Não foi pesado & 5,0 & 115 & 23 & $19^{\circ}$ & 9 & 4 \\
\hline 4 & Estiagem & 12 & 14,5 & 5,0 & 195 & 39 & $25^{\circ}$ & 22 & 7 \\
\hline 5 & Estiagem & 15,5 & 15 & 10 & 320 & 32 & $18^{\circ}$ & 24 & \\
\hline 6 & Estiagem & 12,5 & 10 & 10 & 180 & 18 & $14^{\circ}$ & 22 & \\
\hline 7 & Chuva & 18,7 & 16,2 & 2,5 & 150 & 60 & SS & - & - \\
\hline 8 & Chuva & 20,7 & 17,2 & 2,5 & 150 & 60 & SS & - & - \\
\hline 9 & Chuva & 16,1 & 16,8 & 5,0 & 300 & 60 & SS & - & - \\
\hline 10 & Chuva & 18,1 & 19,9 & 5,0 & 300 & 60 & SS & - & - \\
\hline 11 & Chuva & 12,7 & 15,5 & 10 & 900 & 90 & SS & - & - \\
\hline 12 & Chuva & 19 & 22 & 10 & 900 & 90 & SS & - & - \\
\hline 13 & Chuva & 12,6 & 12,7 & 20 & 140 & 7 & $4^{\circ}$ & 8 & 5 \\
\hline 14 & Chuva & 13,5 & 13,6 & 20 & 160 & 8 & $5^{\circ}$ & 8 & 5 \\
\hline 15 & Chuva & 12,4 & 11,3 & 30 & 240 & 8 & $5^{\circ}$ & 9 & 6 \\
\hline 16 & Chuva & 11 & 11,3 & 30 & 240 & 8 & $5^{\circ}$ & 8 & 5 \\
\hline 17 & Controle & Não foi pesado & Não foi pesado & & & & & SS & \\
\hline 18 & Controle & Não foi pesado & Não foi pesado & & & & & SS & \\
\hline
\end{tabular}

a SS = Sem sinais clínicos. 
Quadro 2. Toxicidade de Ipomoea asarifolia para caprinos. Doses da planta dessecada, colhida na época de estiagem, ingeridas por cada caprino, peso do animal no início e no final da administração, observação dos sinais clínicos e recuperação dos animais

\begin{tabular}{cccccccccc}
\hline $\begin{array}{c}\text { Caprino } \\
\text { no. }\end{array}$ & $\begin{array}{c}\text { Época de } \\
\text { coleta da } \\
\text { planta }\end{array}$ & $\begin{array}{c}\text { Peso inicial } \\
(\mathrm{kg})\end{array}$ & $\begin{array}{c}\text { Peso final } \\
(\mathrm{kg})\end{array}$ & $\begin{array}{c}\text { Dose } \\
\text { diária } \\
(\mathrm{g} / \mathrm{kg})\end{array}$ & $\begin{array}{c}\text { Dose } \\
\text { total } \\
(\mathrm{g} / \mathrm{kg})\end{array}$ & $\begin{array}{c}\text { Dias de } \\
\text { ingestão }\end{array}$ & $\begin{array}{c}\text { Início dos } \\
\text { sinais clí- } \\
\text { nicos (dia) }\end{array}$ & $\begin{array}{c}\text { Duração dos } \\
\text { sinais clíni- } \\
\text { cos (dias) }\end{array}$ & $\begin{array}{c}\text { Recuperação } \\
\text { (dias após } \\
\text { o final da } \\
\text { ingestão) }\end{array}$ \\
\hline 1 & Estiagem & 9,4 & 10,7 & $1,7 \mathrm{~b}$ & 102 & 60 & $\mathrm{SS}$ & - & - \\
$2^{\mathrm{a}}$ & Estiagem & 7,3 & 6,8 & 1,7 & 69,7 & 41 & $\mathrm{SS}$ & - & - \\
3 & Estiagem & 7,6 & 9,3 & 1,7 & 102 & 60 & $\mathrm{SS}$ & - & - \\
4 & Estiagem & 10 & 12,5 & 2,0 & 180 & 90 & $\mathrm{SS}$ & - & - \\
5 & Estiagem & 15,5 & 17,7 & 2,0 & 180 & 90 & $\mathrm{SS}$ & - & - \\
6 & Estiagem & 21 & 20,6 & 3,4 & 34 & 10 & 60 & 11 & 7 \\
7 & Estiagem & 22 & 20,1 & 3,4 & 68 & 20 & 170 & 8 & 5 \\
8 & Estiagem & 15,5 & 15,5 & 5,1 & 71,4 & 14 & 90 & 13 & 8 \\
9 & Estiagem & 14,5 & 14,8 & 5,1 & 81,6 & 16 & $111^{\circ}$ & 8 & - \\
10 & Controle & 14 & 14,5 & - & - & 0 & SS & - & - \\
11 & Controle & 13 & 14 & - & - & 0 & $\mathrm{SS}$ & - & -
\end{tabular}

a $\mathrm{O}$ animal morreu quando ingeria a planta, por que ocorreu falsa via, porém ainda não apresentava sinais clínicos; ${ }^{\mathrm{b}} 1.7,2$, 3.4 , e $5.1 \mathrm{~g} / \mathrm{kg}$ de planta seca representaram, respectivamente, $8.5,10,17$ e $25.5 \mathrm{~g} / \mathrm{kg}$ de planta fresca; ${ }^{\mathrm{c}} \mathrm{SS}=\mathrm{Sem}$ sinais clínicos.

fixadas em solução de tetróxido de ósmio tamponada com cacodilato de sódio, desidratadas em etanol e incluídas em Epon. Cortes semi-finos foram corados com azul de metileno e cortes ultra-finos selecionados, foram contrastados com acetato de uranila e citrato de chumbo e examinados em microscópio eletrônico de transmissão.

Eliminação pelo leite do princípio ativo de Ipomoea asarifolia

Foram utilizadas 7 ovelhas deslanadas, sem raça definida, sendo 5 experimentais e 2 controles. Três ovelhas prenhes e duas paridas receberam I. asarifolia fresca. As doses e o tipo de planta administrada, colhida na época chuvosa, apresentam-se no Quadro 4. Após o parto, os cordeiros ficaram junto com as mães para que mamassem o colostro e o leite espontaneamente, a fim de determinar se o principio ativo da $I$. asarifolia é excretado pelo leite e foram observados diariamente para identificação de sinais da intoxicação.

\section{RESULTADOS}

Os resultados das administrações de diferentes doses de planta fresca e seca a caprinos e ovinos constam nos Quadros 1, 2, 3, 4 e 5.

Os sinais clínicos observados nos caprinos e ovinos caracterizavam-se por tremores musculares discretos dos membros e cabeça que se agravavam em 2-3 dias. Em ambas as espécies foram observados balançar de cabeça e pescoço, hipersensibilidade a ruídos ou movimentos, hipermetria, ataxia e permanência com os membros abertos ou ficando deitado por longos períodos. Quando os animais eram movimentados ou assustados a incoordenação agravava-se e observaram-se andar de lado e quedas, às vezes em posições inusuais. Os ovinos apresentaram nistagmo e midríase e os caprinos pêlos arrepiados. Os animais não deixaram de se alimentar, havendo perda de peso somente em alguns caprinos (Quadro 1). Nas oveIhas houve perda de peso após o parto, porém poderia ter sido associada ao balanço energético negativo durante a lactação. Os cordeiros permaneceram mamando o colostro

Quadro 3. Toxicidade de Ipomoea asarifolia para ovinos. Dose da planta fresca, colhida na época de estiagem e de chuva, ingeridas por cada ovino, peso do animal no início e no final da administração, observação dos sinais clínicos e recuperação dos animais

\begin{tabular}{|c|c|c|c|c|c|c|c|c|c|}
\hline $\begin{array}{l}\text { Ovino } \\
\text { no. }\end{array}$ & $\begin{array}{c}\text { Época de } \\
\text { coleta da } \\
\text { planta }\end{array}$ & $\begin{array}{c}\text { Peso inicial } \\
(\mathrm{kg})\end{array}$ & $\begin{array}{c}\text { Peso final } \\
(\mathrm{kg})\end{array}$ & $\begin{array}{l}\text { Dose } \\
\text { diária } \\
(\mathrm{g} / \mathrm{kg})\end{array}$ & $\begin{array}{l}\text { Dose } \\
\text { total } \\
(\mathrm{g} / \mathrm{kg})\end{array}$ & $\begin{array}{l}\text { Dias de } \\
\text { ingestão }\end{array}$ & $\begin{array}{l}\text { Início dos } \\
\text { sinais clí- } \\
\text { nicos (dia) }\end{array}$ & $\begin{array}{c}\text { Duração dos } \\
\text { sinais clíni- } \\
\text { cos (dias) }\end{array}$ & $\begin{array}{c}\text { Recuperação } \\
\text { (dias após } \\
\text { o final da } \\
\text { ingestão) }\end{array}$ \\
\hline 1 & Estiagem & 40 & 40,8 & 5 & 160 & 32 & $26^{\circ}$ & 14 & 8 \\
\hline 2 & Estiagem & 40 & 41,2 & 5 & 185 & 37 & $31^{\circ}$ & 15 & 9 \\
\hline 3 & Chuva & 12 & 14,4 & 2,5 & 150 & 60 & $S^{b}$ & - & - \\
\hline 4 & Chuva & 16 & 17,36 & 2,5 & 150 & 60 & SS & - & - \\
\hline 5 & Chuva & 22,4 & 24,1 & 5,0 & 300 & 60 & SS & - & - \\
\hline 6 & Chuva & 14 & 14,7 & 5,0 & 300 & 60 & SS & - & - \\
\hline 7 & Chuva & 27 & 29,2 & 10 & 190 & 19 & $13^{\circ}$ & 16 & 10 \\
\hline 8 & Chuva & 30 & 31,2 & 10 & 210 & 21 & $15^{\circ}$ & 16 & 10 \\
\hline 9 & Chuva & 27 & 30,5 & 20 & 260 & 13 & $5^{\circ}$ & 18 & 11 \\
\hline $10^{a}$ & Chuva & 17,1 & 20,6 & 20 & 360 & 18 & $5^{\circ}$ & 13 & - \\
\hline 11 & Controle & Não foi pesado & & & & SS & & & \\
\hline 12 & Controle & Não foi pesado & & & & SS & & & \\
\hline
\end{tabular}

a $\mathrm{O}$ animal ingeriu a planta durante 13 dias e no $14^{\circ}$ dia foi sacrificado; ${ }^{\mathrm{b}} \mathrm{SS}=\mathrm{Sem}$ sinais clínicos. 
Quadro 4. Dose de Ipomoea asarifolia ingerida por cada ovelha, peso do animal no início e no final da administração da planta, observação dos sinais clínicos e recuperação

\begin{tabular}{|c|c|c|c|c|c|c|c|c|c|c|}
\hline $\begin{array}{l}\text { Ovino } \\
\text { no. }\end{array}$ & $\begin{array}{c}\text { Época de } \\
\text { coleta da } \\
\text { planta }\end{array}$ & $\begin{array}{c}\text { Peso } \\
\text { inicial } \\
(\mathrm{kg})\end{array}$ & $\begin{array}{l}\text { Peso } \\
\text { final } \\
(\mathrm{kg})\end{array}$ & $\begin{array}{l}\text { Parto (dias } \\
\text { após o início } \\
\text { da ingestão } \\
\text { da planta) }\end{array}$ & $\begin{array}{l}\text { Dose diária } \\
\quad(\mathrm{g} / \mathrm{kg})\end{array}$ & $\begin{array}{l}\text { Dose } \\
\text { total } \\
(\mathrm{g} / \mathrm{kg})\end{array}$ & $\begin{array}{l}\text { Dias de } \\
\text { ingestão }\end{array}$ & $\begin{array}{l}\text { Início dos } \\
\text { sinais clí- } \\
\text { nicos (dia) }\end{array}$ & $\begin{array}{l}\text { Duração dos } \\
\text { sinais clíni- } \\
\text { cos (dias) } \\
\text { ingestão) }\end{array}$ & $\begin{array}{c}\text { Recuperação } \\
\text { (dias após } \\
\text { o final da }\end{array}$ \\
\hline $13^{a}$ & Chuva & 35,8 & 28,2 & 1 & $\begin{array}{c}5 \mathrm{~g} / \mathrm{kg} \text { (1 dia) } \\
10 \mathrm{~g} / \mathrm{kg}(18 \mathrm{dias})\end{array}$ & 185 & 19 & $14^{\circ}$ & 16 & 11 \\
\hline 14 & Chuva & 41,5 & 40,3 & 0 & 10 & 160 & 16 & $10^{\circ}$ & 20 & 14 \\
\hline 15 & Chuva & 29,4 & 27,1 & 0 & 10 & 180 & 18 & $11^{\circ}$ & 17 & 10 \\
\hline $16^{\mathrm{b}}$ & Estiagem & 35 & 34,1 & 60 & $\begin{array}{c}5 \mathrm{~g} / \mathrm{kg} \text { (31 dias) } \\
2,5 \mathrm{~g} / \mathrm{kg} \text { (24 dias) }\end{array}$ & 215 & 55 & $28^{\circ}$ & 17 & 14 \\
\hline $17^{\mathrm{C}}$ & Estiagem & 36 & 33,2 & 60 & $\begin{array}{c}5 \mathrm{~g} / \mathrm{kg} \text { (25dias) } \\
2,5 \mathrm{~g} / \mathrm{kg} \text { (29 dias) }\end{array}$ & 197,5 & 54 & $22^{\circ}$ & 17 & 13 \\
\hline 18 & Controle & 36,3 & 34,1 & - & - & - & - & - & - & - \\
\hline 19 & Controle & 39,8 & 37 & - & - & - & - & - & - & - \\
\hline
\end{tabular}

a $\mathrm{O}$ animal ingeriu uma dose de $5 \mathrm{~g} / \mathrm{kg}$, no dia seguinte pariu e começou a ingerir $10 \mathrm{~g} / \mathrm{kg}$ durante 18 dias. ${ }^{\mathrm{b}} \mathrm{O}$ animal começou a ingerir a planta 60 dias antes da parição, na dose de $5 \mathrm{~g} / \mathrm{kg}$; no $28^{\circ}$ dia de administração começou apresentar sinais de toxicose, continuou ingerindo até $031^{\circ}$ dia; nesse dia foi suspensa a administração e o animal passou 14 dias se recuperando; foi reiniciada a administração da planta na dose de $2,5 \mathrm{~g} / \mathrm{kg}$ e no $15^{\circ} \mathrm{o}$ animal pariu, continuando a administração por mais 9 dias. ${ }^{\mathrm{c}} \mathrm{O}$ animal começou a ingerir a planta 60 dias antes da parição, na dose de $5 \mathrm{~g} / \mathrm{kg}$, no $22^{\circ}$ dia de administração começou apresentar sinais de toxicose, continuou ingerindo até $\circ 25^{\circ}$ dia, nesse dia parou a administração e o animal passou 13 dias se recuperando. A administração foi reiniciada na dose de $2,5 \mathrm{~g} / \mathrm{kg}$ e no $22^{\circ}$ dia, o animal pariu, continuando a ingestão por mais 7 dias.

e o leite durante todo experimento e não apresentaram nenhum sinal de toxicose. A recuperação de todos os sinais clínicos dos três experimentos foi gradual sendo por último a desaparecer os tremores musculares. O Ovino 10 que recebeu $20 \mathrm{~g} / \mathrm{kg} /$ dia durante 13 dias foi eutanasiado no $14^{\circ}$ dia. Não foram observadas lesões significativas macroscópicas e histológicas. Na ultra-estrutura, alguns dendritos das células de Purkinje exibem tumefação focal e perda de espículas. A tumefação foi acompanhada por diminuição dos neurotúbulos, neurofilamentos, vacuolizações do dendroplasma, e dilatação do retículo endoplasmático liso. Inclusões granulares eletro densas com $2-4 \mu \mathrm{m}$ foram observados no interior de dendritos tumefeitos (Fig.2). Em espículas remanescentes o colo estava encurtado e

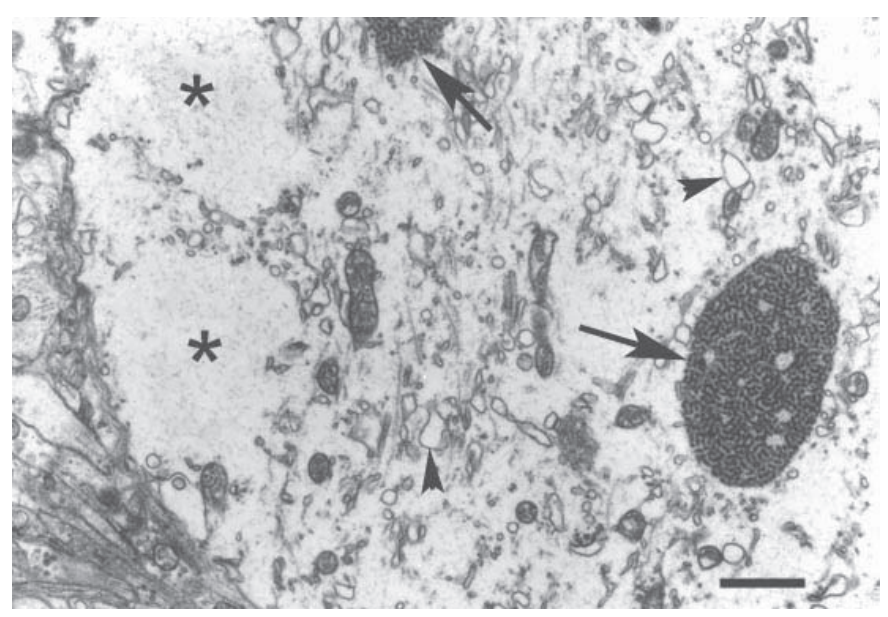

Fig.2. Cerebelo (Ovino 10). Corte transversal de um dendrito de célula de Purkinje Duas inclusões granulares (seta) e vacúolos (asterisco) em um dendroplasma flocular. Não são observadas espículas. Rarefação de neurotubulos e neurofilamentos. Dilatação das cisternas do retículo endoplasmático liso (cabeça de seta). Barra: $1 \mu \mathrm{m}$

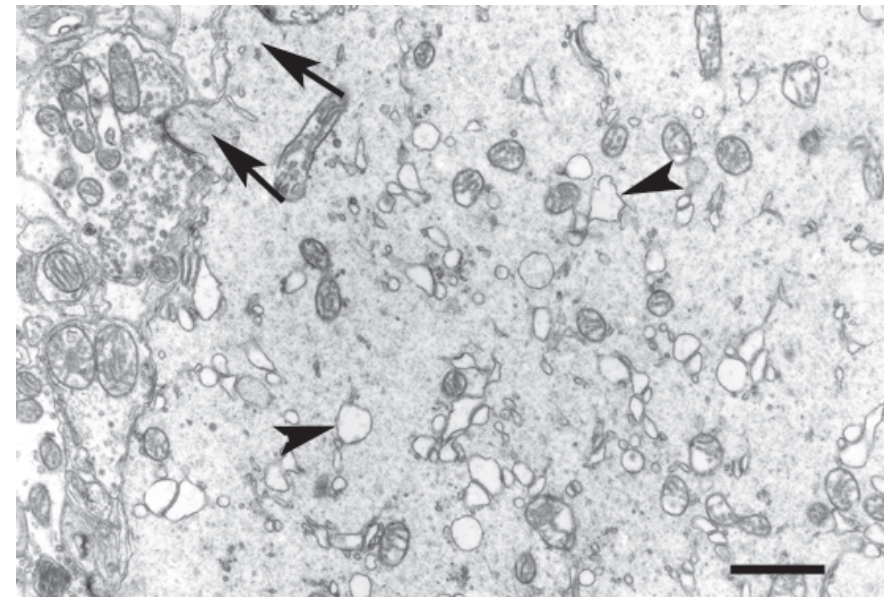

Fig.3. Cerebelo (Ovino 10). Corte trasversal de um dendrito tumefeito. Acentuada diminuição dos neurotúbulos e neurofilamentos. Dilatação das cisternas do retículo endoplasmático liso. Duas espículas remanescentes mostram um colo mais largo e encurtado e aparelho espícular desorganbizado (seta). Barra: $1 \mu \mathrm{m}$.

mais largo (Fig.3) e o aparelho espicular geralmente estava tumefeito e desorganizado. Tumefação dos processos astrocitários era bem evidente. Foram também observados dendritos de células de Purkinje bem preservados, com distribuição irregular em cortes de amostras da mesma ovelha (Fig.4).

A I. asarifolia verde recém-colhida no periodo de estiagem e no período de chuva, quando dessecada, ficou reduzido a $20 \%$ e a $20,4 \%$ do seu peso, respectivamente.

\section{DISCUSSÃO}

A reprodução experimental da intoxicação demonstrou que Ipomoea asarifolia causa sinais clínicos semelhantes em 


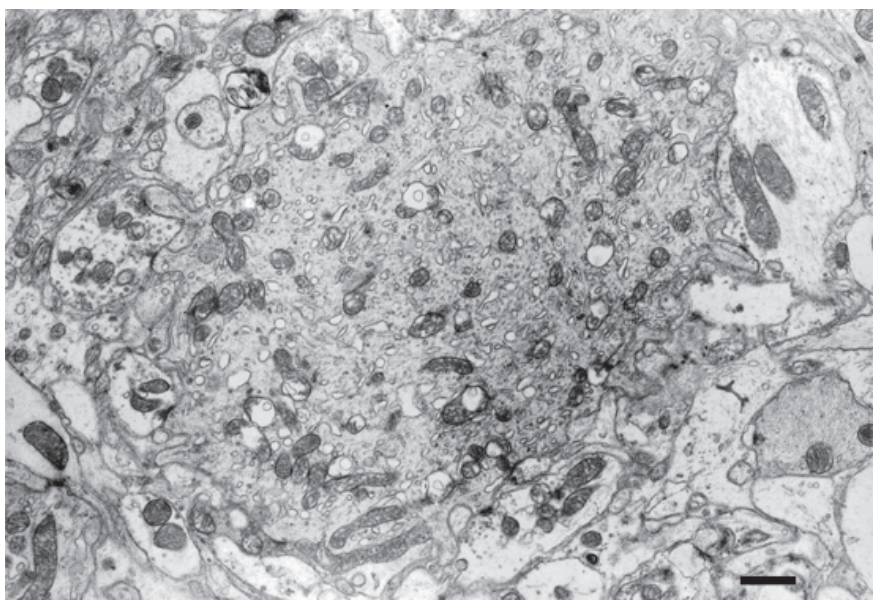

Fig.4. Cerebelo (Ovino 10). Dendrito de célula de Purkinje. Elementos do citosqueleto e espículas estão bem preservados. Observa-se ausência de vacúolos e inclusões. Barra: $2 \mu \mathrm{m}$.

caprinos e ovinos. No entanto, pareceria que os ovinos são mais sensíveis, já que se intoxicaram com $5 \mathrm{~g} / \mathrm{kg}$ (Experimento 4) e 10 $/ \mathrm{kg}$ (Experimento 3) de planta colhida na época de chuva, o que não aconteceu com os caprinos que somente apresentaram sinais após a ingestão de doses diárias de $20 \mathrm{~g} / \mathrm{kg}$ na chuva (Experimento 1). Esta maior susceptibilidade dos ovinos à intoxicação pode explicar, pelo menos em parte, o fato de que os ovinos são mais freqüentemente afetados do que os caprinos (Riet-Correa et al. 2003, Barbosa et al. 2005). Por outro lado, é conhecido que os ovinos jovens são mais afetados que os adultos (Riet-Correa et al. 2006, Guedes et al. 2007). Considerando que neste experimento não houve diferença de toxicidade entre ovinos jovens e adultos pareceria que a maior susceptibilidade dos cordeiros é devida a que estes ingerem mais facilmente a planta.

A intoxicação por $I$. asarifolia ocorre exclusivamente em épocas de estiagem devida, principalmente, à carência de forragem, que faz com que os animais ingiram a planta, que é pouco palatável, mas permanece verde o ano todo, desde que esteja em locais úmidos ou próximo a rios ou açudes. A constatação de que I. asarifolia é menos tóxica na época das chuvas (Quadro 1) sugere que esta menor toxicidade pode ser, também, um fator importante para a não ocorrência da intoxicação durante o inverno.

Segundo Döbereiner et al. (1960), os bovinos e ovinos intoxicados experimentalmente por $l$. asarifolia se recuperam após a parada da ingestão da planta, mas os caprinos geralmente morrem. No entanto, nossos resultados mostraram que a intoxicação é reversível em caprinos e ovinos. A morte de alguns animais em surtos espontâneos deve-se, provavelmente, a que os mesmos não têm condições de alimentar-se e permanecem em decúbito por muito tempo ou a que não são retirados das áreas com a planta. A regressão dos sinais clínicos após a suspensão da ingestão da planta demonstra que a retira- da dos animais das pastagens invadidas por I. asarifolia e um método eficiente para controlar a intoxicação e evitar morte de caprinos e ovinos intoxicados. Nos casos experimentais, os ovinos recuperaram-se em 7-14 dias e os caprinos em 3-8 dias, o que sugere que os ovinos, provavelmente por serem mais sensíveis à intoxicação demoram mais tempo em se recuperar.

Segundo Döbereiner et al. (1960), Medeiros et al. (2003) e Tokarnia et al. (2000) não ocorrem lesões histológicas significantes nos casos de intoxicação por $I$. asarifolia, o que foi constatado, também, no único ovino experimental que foi eutanasiado. No entanto, em casos espontâneos de longa duração encontram-se lesões irreversíveis incluindo degeneração de células de Purkinje e esferóides axonais na camada granular do cerebelo, seguidos de perda de células de Purkinje com vacúolos na camada granular no local onde havia esferóides axonais (Guedes et al. 2007). No estudo ultra-estructural de um animal experimental foram constatadas lesões nas dendritas das células de Purkinje. Tumefação dendrítica aguda e perda de espículas é uma característica patológica de ativação excessiva dos receptores do glutamato ou excitotoxicidade e foram consideradas como um mecanismo de defesa neuronal e são fenômenos reversíveis (Ikegaya et al. 2001). A reversibilidade dos sintomas nas intoxicações espontâneas e experimentais por $I$. asarifolia está de acordo com aquelas observações. Sugere-se que a tumefação dos dendritos com degradação do citosqueleto, diminuição das espículas dendríticas e tumefação dos processos astrocitários, observados na intoxicação por I. asarifolia, seja resultado dos tremores, induzidos pela substância ou substâncias tóxicas contidas na planta, com liberação de glutamato no espaço extracelular que causa excitotoxicidade, o que provavelmente é um mecanismo de defesa neuronal. Não foi encontrada uma explicação para o aparecimento das inclusões granulares nos dendritos tumefeitos. Do nosso conhecimento este é o primeiro relato de tais inclusões em dendritos. A constatação clínica de que depois de ter sido interrompida a administração da planta os sinais regridem e os animais se recuperam, robustece o caráter de reversível da intoxicação e possivelmente das alterações dos dendritos e das células de Purkinje. No entanto, a presença de lesões irreversíveis em alguns casos espontâneos sugere que a reversibilidade das lesões é limitada a um período determinado de tempo, após o qual as lesões tornam-se irreversíveis.

A demonstração de que a planta seca mantém sua toxicidade comprova que a mesma não pode ser administrada como forragem após ser cortada ou fenada. Por outro lado, alguns produtores têm observado que os animais ingerem mais facilmente as folhas secas caídas da planta, o que não evita a intoxicação. Em bovinos, surtos de intoxicação são relatados em animais que consomem a planta seca ou murcha após ter sido arrancada e deixada ao alcance dos mesmos.

Neste trabalho não foi comprovada a hipótese de que 
o princípio ativo da planta passa pelo leite e pode intoxicar os cordeiros, já que no Experimento 4, os cordeiros mamando em ovelhas com sinais clínicos ingerindo $I$. asarifolia não foram afetados.

Agradecimentos.- Este projeto foi financiado pelo Programa Institutos do Milênio (Proc. 420012/2005-2) e pelo Programa de Apoio a Núcleos de Excelência (Pronex, Proc.001/04), CNPq, FAPESQ, MCT. Ao Professor Severo Sales de Barros pela realização da microscopia eletrônica e interpretação de resultados.

\section{REFERÊNCIAS}

Barbosa J.D., Oliveira C.M.C., Duarte M.D., Peixoto P.V. \& Tokarnia C.H. 2005. Intoxicação experimental e natural por Ipomoea asarifolia (Convolvulaceae) em búfalos e outros ruminantes. Pesq. Vet. Bras. 25(4):231-234.

Döbereiner J., Tokarnia C.H. \& Canella C.F.C. 1960. Intoxicação experimental pela "salsa" (Ipomoea asarifolia R. et Schult.). Arqs Inst. Biol. Anim., Rio de J., 3:39-57.

Guedes K.M.R., Riet-Correa F., Dantas A.F.M., Simões S.V.D., Miranda Neto E.G., Nobre V.M.T. \& Medeiros R.M.T. 2007. Doenças do siste- ma nervoso central em caprinos e ovinos no semi-árido. Pesq. Vet. Bras. 27(1):29-30.

Ikegaia Y., Kim J.A., Baba M., Iwatsubo T., Nishiyama N. \& Atsuki N. 2001. Rapid and reversible changes in dendrite morphology and synaptic efficacy following NMDA receptor activation: implication for a cellular defense against excitotoxicity. J. Cell Sci. 114:4083-4093.

Kissmann K.G. \& Groth D. 1992. Plantas Infestantes e Nocivas. BASF Brasileira S.A., São Paulo, p.683-685.

Medeiros R.M.T., Barbosa R.C., Riet-Correa F., Lima E.F., Tabosa I.M., Barros S.S., Gardner D.R. \& Molyneux R.J. 2003. Tremorgenic syndrome in goats caused by, Ipomoea asarifolia in northeastern Brazil. Toxicon 41:933-935.

Riet-Correa F., Tabosa I.M., Azevedo E.O., Medeiros R.M.T., Simões S.V.D., Dantas A.F.M., Alves C.J., Nobre V.M.T., Athayde A.C.R., Gomes A.A. \& Lima E.F. 2003. Doenças dos ruminantes e eqüinos no semi-árido da Paraíba, Semi-árido em Foco 1(1):58-60.

Riet-Correa F., Medeiros R.M.T. \& Dantas A.F.M. 2006. Plantas Tóxicas da Paraíba. Universidade Federal de Campina Grande, CSTR/ HV, SEBRAE/PB, Patos. 58p.

Tokarnia C.H., Döbereiner J. \& Peixoto P.V. 2000. Plantas Tóxicas do Brasil. Editora Helianthus, Rio de Janeiro, p.123-125. 